\title{
Koroner Bypass Greftleme Cerrahisi Sonrası Gelişen Akut Böbrek Hasarının RIFLE Sınıflamasıyla Tanımlanması: Risk Belirteçleri ve Sonuçları
}

\section{Definition of Acute Renal Injury with RIFLE Classification That Occurs After Coronary Bypass Surgery: Risk Markers and Results}

\author{
$\underline{\text { Mehmet Erin TÜYSÜZ }}{ }^{1}$ (D), Mehmet DEDEMOĞLU 1
}

\begin{abstract}
1Mersin Şehir Eğitim ve Araşıırma Hastanesi, Kalp ve Damar Cerrahisi Bölümü, Mersin
2 Mersin Şehir Eğitim ve Araştırma Hastanesi, Pediatrik Kalp ve Damar Cerrahisi Bölümü, Mersin
\end{abstract}

öz.

Amaç: RIFLE sınıflamasını kullanarak Koroner arter bypass greftleme (KABG) cerrahisi sonrasında gelişen akut böbrek hasarını $(A B H)$ tanımlamak, hasar gelişmiş hastaların erken ve geç dönem mortalitelerine etki eden risk faktörlerini belirlemektir.

Materyal ve Metod: Kliniğimizde Şubat 2016 ile Eylül 2018 yılları arasında izole KABG operasyonu yapılan 213 hasta geriye dönük olarak incelendi. Tüm hastaların operasyon öncesi ve sonrası tahmini glomeruler filtrasyon hızları hesaplandı. ABH'nin tanıSı ve ciddiyeti, RIFLE sınıflaması ile belirlendi.

Bulgular: Çalışmaya dâhil edilen hastaların medyan yaşı 62 yıldı, hastaların 144'ü $(\% 67,6)$ erkekti. Postoperatif dönemde, RIFLE sınıflamasına göre $65(\% 30,5)$ hastada ABH saptandı. Hastaların \%63,1'i evre R, \%23,1'i evre $\mathrm{I}, \% 13,8^{\prime} \mathrm{i}$ ise $\mathrm{F}$ evresindeydi. ABH'nin $\mathrm{L}$ ve $\mathrm{E}$ evresi hiçbir hastada gelişmedi. Diyabetes mellitus, hipertansiyon, konjestif kalp yetmezliği, periferik arter hastalı̆ı̆ gibi komorbid faktörler ve kardiyopulmoner bypass (KPB) süresi ABH gelişiminde bağımsız risk faktörleri olarak saptandı. $A B H$ bulunan grupta $A B H$ bulunmayan gruba göre post operatif dönemde kanama revizyonu, hemodiyaliz intiyacı, intraaortik balon pompası kullanımı ve solunumsal komplikasyonlar daha fazlaydı. Ek olarak, hastane içi ve geç dönem mortalite oranları ABH olan grupta daha yüksekti. Hastaların sağkalım oranları ABH'nin ciddiyeti arttıkça düştü. Evre F'deki hastalar en düşük sağkalım oranına sahipti.

Sonuç: RIFLE sınıflaması, KABG cerrahisi sonrası gelişen ABH'yi gösteren maliyeti düşük ve kolay uygulanabilir bir araçtır ve böbrek hasarııın başlangıç evresinde saptanmasına yardımcı olur. Bu sınıflama, KABG cerrahisi sonrası $\mathrm{ABH}$ gelişen hastaların mortalite ve morbiditesi hakkında öngörü sağlar.

Anahtar kelimeler: Akut böbrek hasarı, Koroner arter bypass greftleme, RIFLE sınıflaması

Abstract

Background: To define acute kidney injury (AKI) that develops following coronary artery bypass grafting (CABG) surgery using RIFLE classification system and to determine the risk factors affecting the early and late mortality of the patients who developed acute kidney injury.

Materials and Methods: A total of 213 patients who underwent isolated CABG operation in our clinic between February 2016 and September 2018 were retrospectively investigated. Preoperative and postoperative estimated glomerular filtration rates were calculated for all patients. The diagnosis and severity of AKI was determined by RIFLE classification.

Results: The median age of the patients included in the study was 62 , of whom 114 were male. In the postoperative period, AKI was detected in $65(30.5 \%)$ patients according to RIFLE classification. $63.1 \%$ of the patients were in stage $\mathrm{R}, 23.1 \%$ were in stage I, $13.8 \%$ were in stage $\mathrm{F}$. L and $\mathrm{E}$ stages of AKI did not develop in any patients. Comorbid conditions such as diabetes mellitus, hypertension, congestive heart failure and peripheral artery disease, and the duration of cardiopulmonary bypass (CPB) were detected to be independent risk factors for the development of AKI. Bleeding revision need for hemodialysis, usage of intra aortic balloon pump and respiratory complications were higher in the AKI group than in the non-AKI group. In addition, in-hospital and long term mortality rates were significantly higher in AKI group. As the severity of AKI increased, the survival rates of the patients were decreased. The patients in stage $-\mathrm{F}$ had the lowest survival rate.

Conclusion: RIFLE classification is a low-cost and easy-to-use tool to detect AKI developing after CABG surgery and it helps to detect kidney injury at the initial stage. This classification provides a prediction about the mortality and morbidity of the patients who developed AKI following CABG surgery.

Key words: Acute kidney injury, Coronary artery bypass grafting, RIFLE classification
Sorumlu Yazar $I$

Corresponding Author

Dr. Mehmet Erin TÜYSÜZ

Mersin Şehir Eğitim ve Araştırma Hastanesi,

Korukent Mah, 96015 Cad,

Mersin/Türkiye 33240

Telefon: 05053396598

e-mail: drmehmeterin@yahoo.com

Geliş tarihi / Received:

19.07.2019

Kabul tarihi / Accepted:

22.11.2019

DOI: 10.35440/hutfd.594147 


\section{Giriş}

Akut böbrek hasarı $(A B H)$, kalp cerrahisi sonrası gelişen en yaygın komplikasyonlardan biridir ve insidansı \%542'dir (1-3). ABH, postoperatif dönemde mortalite ve morbiditenin artmasına neden olur (4). Bu nedenle hasar gelişmeden bu komplikasyonun öngörülmesi ve önlemlerin alınması gerekmektedir. Koroner arter bypass greftleme (KABG) cerrahisi sonrasında da bu komplikasyon görülebilmektedir. Diyabet, kronik obstrüktif akciğer hastalığı (KOAH), ileri yaş ve operasyon sırasında kardiyopulmoner bypass (KPB) kullanımı, postoperatif dönemde renal hasarın gelişimine neden olan faktörlerdir (5-7).

Akut böbrek yetmezliği (ABY) terminolojisi, kardiyak cerrahi pratiğinde daha çok kullanılan bir tanımlamadır. Ancak, $A B Y$ oligüri ya da anüri gelişmiş ileri derecedeki böbrek fonksiyon bozukluğunu tanımlamaktadır (8) ve bu tanımlama böbrek hasarının belli evrelerini içermemektedir (9-12). Böbrek fonksiyon bozukluğunun farklı derecelerini tanımlamak için günümüzde $A B H$ terminolojisi daha sık kullanılmaya başlanmıştır (13). ABH tanımlaması sayesinde, hasarın organ fonksiyon bozukluğuna yol açmadan tespit edilmesi ve daha basit önlemlerle hasarın ilerlemesi engellenebilir. Acute Dialysis Quality Initiative (ADQI) tarafından $A B H$ 'nin uniform tanımlanması için, $R$ (risk), I (injury-hasar), F (failure-yetmezlik), L (loss-kayıp) ve $E$ (end stage kidney disease-son dönem böbrek yetmezliği) akronimleri ile RIFLE sınıflaması yayınlanmıştır (14). Bu sınıflamada temel alınan unsurlar, serum kreatinin düzeyi, tahmini glomeruler filtrasyon hızı (t-GFH) ve idrar çıkış miktarındaki değişimlerdir (15).

Çalışmamızın amacı, koroner arter bypass greftleme (KABG) cerrahisini takiben gelişen $A B H$ 'nin insidansını ve şiddetini RIFLE kriterleri ile tanımlamak ve $A B H$ 'ye etki eden bağımsız prediktörleri incelemektir. Bunlara ek olarak, ABH'nin postoperatif erken (hastane içi) ve geç dönem mortalite ile ilişkisinin araştırıması da amaçlanmıştır.

\section{Materyal ve Metot Hastalar}

Enstitümüzün Bilimsel Araştırmalar İin Komisyonu tarafindan 65355327-604.01.02-E.348 no'lu karar numarasıyla etik kurul onayı verilmiştir.

Hastanemiz Kalp ve Damar Cerrahisi kliniğinde Şubat 2016 ile Eylül 2018 yılları arasında KABG operasyonu yapılan tüm olgular geriye dönük olarak incelendi. Çalışmaya elektif ya da acil izole KABG operasyonu uygulanan 213 ardışık vaka dâhil edildi. Diğer kardiyak cerrahi operasyonlar, redo KABG operasyonları, akut ya da kronik böbrek hastalığı öyküsü olanlar, operasyon öncesi hemodinamisi stabil olmayan ve ileri yaşam destek intiyacı olan hastalar çalışma dışı bırakıldı.

Klinik veriler, hastane kayıtları ve hasta dosyalarından edinildi. Hastaların karakteristik bulgularına hasta özgeç- mişi, fizik muayene bulguları, laboratuvar, görüntüleme yöntemleri ve hastane izlem formlarından ulaşıldı. Hastalarla yapılan telefon görüşsmelerinden ve Ullusal Ölüm Bildirim Sistemi'nden geç dönem sağkalım bilgisi elde edildi. Preoperatif dönemdeki tanımlamalar şu şekilde yapıldı. Konjestif kalp yetmezliğinin (KKY) klinik semptom ve bulgularına sahip olup Ejeksiyon fraksiyonu (EF) $\% 35$ 'in altında olan hastalar KKY olarak adlandırıldı. Hipertansiyon, istirahatte sistolik arter basıncının 140, diyastolik arter basıncının $90 \mathrm{mmHg}$ 'nin üzerinde olması ve/veya en az bir antihipertansif tedavisi alınması olarak tanımlandı. Diabetes mellituslu (DM), açlık kan glikozunun $\geq 126 \mathrm{mg} / \mathrm{dl}$ 'nin üzerinde olması ve buna yönelik herhangi bir tedavi alınması olarak tanımlandı. Hastaların preoperatif dönemde nefrotoksik ilaç kullanım öyküleri yoktu.

\section{Cerrahi yöntem ve postoperatif bakım}

Tüm operasyonlar genel anestezi eşliğinde KPB cihazı kullanılarak standart kalp cerrahisi prosedürüyle gerçekleştirildi. Median sternotomiyi takiben left internal mammarian arter (LIMA) ve eş zamanlı safen ven greftleri hazırlandı. Perikard açıldıktan sonra, aortadan arteryel, sağ atriyumdan venöz kanülasyon yapılarak KPB'ye girildi. Ilımlı hipotermi sağlandıktan sonra aortaya kros klemp konuldu. Kalp, antegrad yoldan verilen potasyumlu soğuk kardiyopleji ile arrest edildi. Kardiyopleji uygulaması, 20 dakikada bir aralıklı olarak yapıldı. Tüm distal anastomozlar kros klemp altında gerçekleştirildi. Proksimal anastomozlar ise kros klemp alındıktan sonra, kalbin çalışmasını takiben atan kalpte yapıldı. Normotermi ve normal kardiyak fonksiyon sağlandıktan sonra KPB'den çıkıldı. Dekanülasyon ve kanama kontrolünü takiben standart kapatma prosedürüyle operasyon sonlandırıldı. Operasyon sonrası tüm hastalar kalp cerrahisi yoğun bakımında (YBÜ) standart mekanik ventilasyon, kardiyovasküler ve solunumsal monitörizasyon eşliğinde takip edildi.

\section{Böbrek hasarının ve evrelerinin belirlenmesi}

Tüm hastaların operasyon öncesi ve sonrası yedi günlük bazal kreatinin seviyeleri kayıt altına alındı. Her hasta için operasyon öncesi ve sonrasına ait t-GFH, modification of

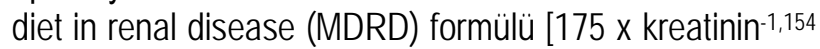
$x$ Yaş-0,203 x 0,742 (eğer kadın ise) x 1,212 (eğer AfroAmerikan ise)] kullanılarak hesaplandı (16). Hastalardaki $A B H$ 'nin belirlenmesi ve ciddiyetinin evrelendirilmesi için RIFLE sınıflaması kullanıldı. Bu sınıflamaya göre; $\% 25$ 'ten fazla t-GFH azalması / serum kreatininde 1,5 kat artış / 6 saatlik idrar miktarı $<0,5 \mathrm{ml} / \mathrm{kg} / \mathrm{sa}$ olması evre $R$ (risk) olarak tanımlanırken, $\% 50$ 'den fazla t-GFH azalması / serum kreatininde 2 kat artış / 12 saatlik idrar miktarı $<0,5 \mathrm{ml} / \mathrm{kg} / \mathrm{sa}$ olması evre I (injury-hasar) olarak tanımlandı. t-GFH'deki $\% 75$ 'ten fazla azalış ya da t-GFH $<35$ $\mathrm{ml} / 1,73 \mathrm{~m}^{2}$ olması / serum kreatininde 3 kat artış / 24 saatlik idrar miktarı $<0,3 \mathrm{ml} / \mathrm{kg} / \mathrm{sa}$ ya da anüri olması evre $F$ (failure-yetmezlik) olarak tanımlanırken 4 haftadan uzun 
süren tamamen böbrek fonksiyon kaybı evre L (losskayıp) ve 3 aydan uzun süren renal replasman terapisi evre $E$ (son dönem böbrek yetmezliği) olarak kabul edildi. Çalışmamızda, $\mathrm{ABH}$ ve evrelerinin tanımlanmasında tGFH kriteri kullanıldı. Çünkü idrar çıkış kriteri, hasta grubumuzda böbrek dışı kardiyak nedenlerden dolayı diüretik kullanımına bağı hatalı sonuç verme olasılığına sahipti ve t-GFH kriteri serum kreatinin kriterine karşı daha duyarlıydi.

\section{İstatistiksel analizler}

Tüm istatistiksel analizler SPSS (Statistical Package fort he Social Sciences) yazilımı kullanılarak yapıldı. Tanımlayıcı istatistiklerde, kategorik değişkenler frekans ve yüzdeyle sayısal değişkenler ise normal dağılmadığı için medyan ve 25-75 çeyrekler arasıyla ifade edildi. Kategorik değişkenlere ait ikili ve üçlü grup karşılaştırmalarında 'Pearson Ki Kare Testi', sayısal değişkenler için ikili grup karşılaştırmalarında 'Man Whitney U Testi', üçlü grup karşılaştırmalarında ise 'Kruskal Wallis Testi' kullanıldı. Sonuç değişkenine ilişkin bağımsız prediktörleri saptamak için 'Univaryant ve Multivaryant Lojistik Regresyon Analizleri' kullanıldı. Univaryant analizde $p$ değeri $<0.1$ olan değişkenler, multivaryant analizde kullanılacak olan modele alındı ve model uyumluluğu için Forward: Wald metodu kullanıldı. Geç dönem sağkalıma ilişkin oranlar ve sağkalım eğrilerini hesaplamak için 'Kaplan Meier Analizi' kullanıldı. Gruplar arası karşılaştırma için 'Log Rank Testi' kullanıldı. Geç dönem takipte sonuç değişkenine ilişkin bağımsız prediktörlerinin saptanmasında 'Cox Proportional Hazard Regresyon Analizi' kullanıldı. Tüm analizlerde $p$ değeri $<0.05$ olması istatistiksel olarak anlamlı kabul edildi.

\section{Bulgular}

Çalışma popülasyonunun demografik özellikleri, $A B H$ ve evrelerinin insidansı ve operatif bulgular

Medyan yaş 62 yıl idi (min: 34, maks: 94) ve erkek cinsiyet çoğunluktaydı $(\% 67,6)$. Medyan takip süresi 1,6 yıldı (min: 0,01, maks: 2,81). Postoperatif dönemde, RIFLE sınıflamasıyla $65(\% 30,5)$ hastada ABH saptandı. Hasarın ciddiyet evrelerinin çoğunluğunu (41 hasta, $\% 63,1)$ evre R oluşturuyordu, $15(\% 23,1)$ hastada evre I, $9(\% 13,8)$ hastada evre $\mathrm{F} A B H$ mevcuttu. Klasik $A B Y$ tanımlamasına göre hastalar incelendiğinde ise, sadece $11(\% 5,2)$ hastada $A B Y$ tespit edildi. Bu oran RIFLE sınıflamasına göre tespit edilen $\mathrm{ABH}$ oranından daha düşüktü. Hastalara ait demografik özellikler Tablo 1'de özetlenmiştir. Buna göre $\mathrm{ABH}$ bulunan grupta istatistiksel anlamlı olarak daha yüksek oranda KKY $(p=0.02)$, periferik arter hastalığı $(p=0.04)$ ve HT öyküsü $(p=0.03)$ mevcuttu. Operatif bulgulara bakıldığında, $\mathrm{ABH}$ olan hasta grubunda $\mathrm{KPB}$ süresi anlamlı olarak daha yüksekti $(p=0.02)$. Diğer operatif bulgularda gruplar arası anlamlı fark saptanmadı (Tablo 2).
$A B H$ ve evrelerinin postoperatif potansiyel komplikasyonlar, Mekanik ventilasyon, YBÜ ve hastane kalış süreleri ile hastane içi mortaliteye olan etkisi

Hastalara ait operasyon sonrası sonuçlar Tablo 3'te gösterilmiştir. $A B H$ olan hastalarda, postoperatif potansiyel komplikasyonlardan solunumsal komplikasyonları $(p=0.04)$, kanama revizyonu $(p=0.02)$, hemodiyaliz uygulama oranları $(p=0.001)$ ve intraaortik balon pompası (IABP) kullanımı $(p=0.03)$ istatistiksel anlamlı olarak daha yüksekti. Ek olarak; $A B H$ olan hastalar, daha yüksek serum kreatinin $(p=0.03)$ ve daha düşük t-GFH seviyelerine sahipti $(p=0.01)$. Dahası, hastane içi mortalite de $\mathrm{ABH}$ olan hasta grubunda anlamlı olarak daha yüksekti ( $p$ $<0.001$ ). RIFLE evrelerine göre postoperatif hemodiyaliz ihtiyacı, hastane içi mortalite ve geç dönem mortalite oranları evre F' de diğer evrelere göre istatiksel anlamlı olarak daha yüksekti (Tablo 4).

Tablo 1. Hastalara ait demografik özellikler

\begin{tabular}{|c|c|c|c|c|}
\hline Değişkenler & $\begin{array}{l}\text { Grup I } \\
\text { (n: 148) }\end{array}$ & $\begin{array}{l}\text { Grup II } \\
\text { (n: 65) }\end{array}$ & $\begin{array}{l}\text { Tüm Hastalar } \\
\text { (n: 213) }\end{array}$ & $\begin{array}{l}\mathbf{P} \\
\text { Değeri }\end{array}$ \\
\hline Yaş (yıl) & $62(54-69)$ & $61(54-68)$ & $62(54-69)$ & 0,62 \\
\hline VKI $\left(\mathrm{kg} / \mathrm{m}^{2}\right)$ & $28(25-31)$ & $29(25-32)$ & $28(25-31)$ & 0,47 \\
\hline $\operatorname{VYA}\left(\mathrm{m}^{2}\right)$ & $1,9(1,8-2,0)$ & $1,9(1,8-2,0)$ & $1,9(1,8-2,0)$ & 0,81 \\
\hline Erkek cinsiyet & $102(68,9)$ & $42(64,6)$ & $144(67,6)$ & 0,54 \\
\hline USAP & $40(27,0)$ & $14(21,5)$ & $54(25,4)$ & 0,40 \\
\hline $\begin{array}{l}\text { Miyokart enfarktüs } \\
\text { öyküsü }\end{array}$ & $48(32,4)$ & $15(23,1)$ & $63(29,6)$ & 0,17 \\
\hline KKY & $8(5,4)$ & $10(15,4)$ & $18(8,5)$ & $0,02^{*}$ \\
\hline Karotis arter hastalığı & $5(3,4)$ & $1(1,5)$ & $6(2,8)$ & 0,46 \\
\hline Periferik arter hastalığı & $4(2,7)$ & $6(9,2)$ & $10(4,7)$ & $0,04^{*}$ \\
\hline Hiperlipidemi & $6(4,1)$ & $3(4,6)$ & $9(4,2)$ & 0,85 \\
\hline Hipertansiyon & $39(26,4)$ & $27(41,5)$ & $66(31,0)$ & $0,03^{*}$ \\
\hline $\mathrm{KOAH}$ & $27(18,2)$ & $17(26,2)$ & $44(20,7)$ & 0,19 \\
\hline Preoperatif SVH & $3(2,0)$ & $2(3,1)$ & $5(2,3)$ & 0,64 \\
\hline Diyabet & $116(78,4)$ & $50(76,9)$ & $166(77,9)$ & 0,81 \\
\hline $\begin{array}{l}\text { Serum kreatinin değeri } \\
(\mathrm{mg} / \mathrm{dl})\end{array}$ & $0,8(0,7-0,9)$ & $0,9(0,7-1,0)$ & $0,8(0,7-1,0)$ & 0,20 \\
\hline t-GFH $\left(\mathrm{ml} / \mathrm{dk} / 1,73 \mathrm{~m}^{2}\right)$ & 95 (76-117) & $86(73-104)$ & $92(76-113)$ & 0,11 \\
\hline Ejeksiyon fraksiyonu (\%) & $50(45-55)$ & $50(40-57)$ & $50(45-55)$ & 0,97 \\
\hline
\end{tabular}

t-GFR: Tahmini glomerüler filtrasyon hızı, KKY: Konjestif kalp yetmezliği,

KOAH: Kronik obstrüktif akciğer hastalığı, SS: Standart sapma,

SVH: Serebro vasküler hastalık, USAP: Unstabil angına pektoris,

VKI: Vücut kitle indeksi, VYA: Vücut yüzey alanı

Grup I: Akut böbrek hasarı olmayan hastalar

Grup II: Akut böbrek hasarı olan hastalar

\section{$A B H$ ve evreler ile beraber hastane içi mortalite için prediktif risk faktörleri}

$\mathrm{ABH}$ evreleri ve hastane içi mortaliteyle ilişkili peroperatif bağımsız risk faktörleri univaryant ve multivaryant analizlerle belirlendi (Tablo 5). Buna göre preoperatif KKY ve HT varlığı, KPB süresi ve postoperatif solunumsal komplikasyon gözlenmesi $\mathrm{ABH}$ ile; preoperatif periferik arter hastalığı ve KOAH varlığı evre R ile; KPB süresi evre I ile, preoperatif KKY varlığı ve postoperatif solunumsal komplikasyon gözlenmesi evre $F$ ile bağımsız bir şekilde ilişkili idi. Yaş, preoperatif KKY, MI öyküsü, KPB süresi, postoperatif $A B H$ gelişimi ve IABP gereksinimi hastane içi mortalite ile ilişkili faktörlerdi.

Geç dönem mortalitenin bağımsız prediktörleri 
Tüm hastalara ait sağkalım eğrisi Şekil 1'de gösterilmiştir. Tüm hastalar için 1 yıllık sağkalım oranı \%93,4'tü. Gruplar arası sağkalım oranı, $\mathrm{ABH}$ olan hasta grubunda anlamlı olarak daha düşüktü ( $p<0.001$, Şekil 2). ABH hasarının ciddiyeti arttı̆ı̆ında bu oran daha da düştü ve evre F'de hastalar istatistiksel anlamlı olarak en düşük sağkalım oranına sahipti ( $p<0.001$, Şekil 3). Yaş, KKY ve MI öyküsü, KPB süresi, postoperatif re-operasyonlar ve $A B H$ gelişimi geç dönem mortalite ile ilişkili faktörlerdi (Tablo $6)$.

Tablo 2. Operatif bulgular

\begin{tabular}{|c|c|c|c|c|}
\hline Değişkenler & $\begin{array}{l}\text { Grup I } \\
\text { (n: 148) }\end{array}$ & $\begin{array}{l}\text { Grup II } \\
\text { (n: 65) }\end{array}$ & $\begin{array}{l}\text { Tüm } \\
\text { Hastalar } \\
\text { (n: 213) }\end{array}$ & $\begin{array}{l}\mathbf{P} \\
\text { Değeri }\end{array}$ \\
\hline Acil cerrahi & $17(11,5)$ & $5(7,7)$ & $22(10,3)$ & 0.40 \\
\hline Greftleme yapılan damar sayısı & & & & 0.95 \\
\hline Tek damar & $11(7,4)$ & $6(9,2)$ & $17(8,0)$ & \\
\hline 2 damar & $30(20,3)$ & $12(18,5)$ & $42(19,7)$ & \\
\hline 3 damar & $71(4,0)$ & $30(46,2)$ & $101(47,4)$ & \\
\hline 4 damar & $27(18,2)$ & $14(21,5)$ & $41(19,2)$ & \\
\hline 5 damar & $9(6,1)$ & $3(4,6)$ & $12(5,6)$ & \\
\hline Retrograd kardiyopleji & $2(1,4)$ & $1(1,5)$ & $3(1,4)$ & 0.92 \\
\hline Hipotermi $\left({ }^{\circ} \mathrm{C}\right)$ & $\begin{array}{l}30 \\
31)\end{array}$ & $\begin{array}{l}30 \\
31)\end{array}$ & $30(30-31)$ & 0.85 \\
\hline KPB zamanı (dk) & $\begin{array}{l}81 \\
101)\end{array}$ & $\begin{array}{l}94 \\
103)\end{array}$ & $87(71-101)$ & $0.02 *$ \\
\hline Kros klemp zamanı (dk) & $\begin{array}{l}47 \\
57)\end{array}$ & $\begin{array}{l}46 \\
58)\end{array}$ & $47(35-57)$ & 0.89 \\
\hline
\end{tabular}

KPB: Kardiyo pulmoner bypass, SS: Standart sapma

Grup I: Akut böbrek hasarı olmayan hastalar

Grup II: Akut böbrek hasarı olan hastalar

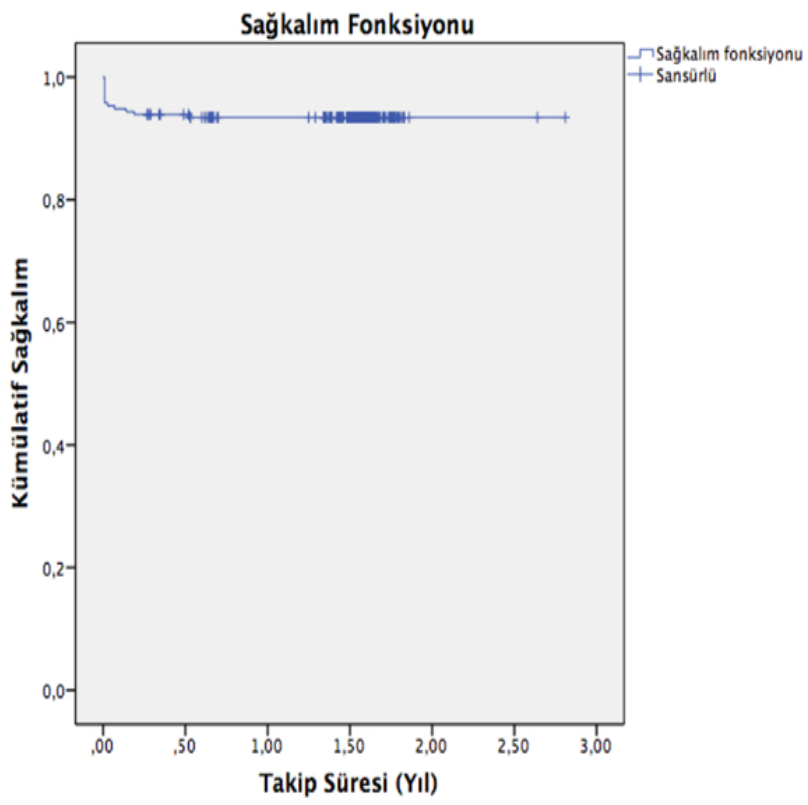

Şekil 1. Tüm hastalara ait sağkalım eğrisi

\section{Tartışma}

$\mathrm{Bu}$ çalışmada, KABG sonrası gelişen ABH'yi, RIFLE sınıflamasıyla evrelendirdik. Bu evrelemenin sonucunda mortalite ve morbiditeye etki eden risk faktörlerini belirledik. $\mathrm{ABH}$ gelişen grupta hastane içi ve geç dönem mortalite oranlarının anlamlı olarak daha yüksek olduğunu ve evre F'deki hastaların en yüksek mortalite oranına sahip olduğunu tespit ettik. DM, HT, KKY, periferik arter hastalığı gibi komorbid faktörler ve KPB süresi $\mathrm{ABH}$ gelişimine etki eden bağımsız risk faktörleriydi.

RIFLE sınıflaması ABH'nin varlığı ve şiddetinin derecelendirmesinde kullanılan yeni bir sıniflama sistemidir. Çalışmamızda, RIFLE sınıflamasına göre değerlendirdiğimiz hastalarda $\mathrm{ABH}$ oranı $\% 30,5$ seviyelerindeydi. Klâsik $A B Y$ tanımlamasına göre aynı hastaları incelediğimizde ise, bu oran sadece \%5,2 idi. Bu fark, klâsik ABY tanımlamasının böbrek hasarının erken dönemlerini saptayamamasından kaynaklanmaktadır. RIFLE sınıflamasıyla, böbrek fonksiyonları henüz tam olarak bozulmadan önce gelişen $A B H$ saptanabilir. RIFLE sınıflaması ile $A B H$ 'nin saptanmasında temel alınan kriterler serum kreatinini, t-GFH ve idrar çıkışının miktarıdır (17). $A B H$ varlığında, t-GFH değerindeki değişiklikler serum kreatinin değerindeki değişikliklere göre daha duyarlıdır. Ek olarak idrar çıkış kriteri de kullanılan diüretik ilaçlar nedeniyle değişkenlik gösterebilir ve bu da sonuçların yanlış yorumlanmasına yol açabilir (18). Bu nedenle, biz bu çalışmamızda t-GFH kriterini kullandık.

Tablo 3. Postoperatif sonuçlar

\begin{tabular}{|c|c|c|c|c|}
\hline Değişkenler & $\begin{array}{l}\text { Grup I } \\
\text { (n: 148) }\end{array}$ & $\begin{array}{l}\text { Grup II } \\
\text { (n: 65) }\end{array}$ & $\begin{array}{l}\text { Tüm Hastalar } \\
\text { (n: 213) }\end{array}$ & $\begin{array}{l}\mathbf{P} \\
\text { Değeri }\end{array}$ \\
\hline $\begin{array}{l}\text { Greft trombozu nedeniyle } \\
\text { erken reoperasyon }\end{array}$ & $3(2,0)$ & $4(6,2)$ & $7(3,3)$ & 0.12 \\
\hline IABP & $5(3,4)$ & $7(10,8)$ & $12(5,6)$ & $0.03^{*}$ \\
\hline $\begin{array}{l}\text { Düşük kardiyak debi } \\
\text { sendromu }\end{array}$ & $20(13,5)$ & $12(18,5)$ & $32(15,0)$ & 0.35 \\
\hline Atriyal fibrilasyon & $35(23,6)$ & $17(26,2)$ & $52(24,4)$ & 0.70 \\
\hline Diğer aritmiler & & & & 0.43 \\
\hline Ventriküler fibrilasyon & $1(0,7)$ & $2(3,1)$ & $3(1,3)$ & \\
\hline Ventriküler taşikardi & $1(0,7)$ & $1(1,5)$ & $2(0,9)$ & \\
\hline $\begin{array}{l}\text { Supra-ventrüküler } \\
\text { taşikardi }\end{array}$ & $2(1,4)$ & 0 & $2(0,9)$ & \\
\hline Ventriküler ekstra sistol & $1(0,7)$ & 0 & $1(0,5)$ & \\
\hline Sinüs taşikardisi & $1(0,7)$ & 0 & $1(0,5)$ & \\
\hline $\begin{array}{l}\text { Solunumsal komplikasyon- } \\
\text { lar }\end{array}$ & $13(8,8)$ & $12(18,5)$ & $25(11,7)$ & $0.04^{*}$ \\
\hline Nörolojik komplikasyonlar & $9(6,1)$ & $4(6,2)$ & $13(6,1)$ & 0.98 \\
\hline Kanama revizyonu & $2(1,4)$ & $5(7,7)$ & $7(3,3)$ & $0.02^{*}$ \\
\hline Sepsis & $10(6,8)$ & $6(9,2)$ & $16(7,5)$ & 0.53 \\
\hline Hemodiyaliz & 0 & $5(7,7)$ & $5(2,3)$ & $0.001^{*}$ \\
\hline Serum kreatinin (mg/dl) & $0,8(0,7-1,0)$ & $\begin{array}{l}0,9 \\
1,1)\end{array}$ & $0,9(0,7-1,0)$ & $0.03^{*}$ \\
\hline $\mathrm{t}-\mathrm{GFH}\left(\mathrm{ml} / \mathrm{dk} / 1,73 \mathrm{~m}^{2}\right)$ & $92(75-112)$ & $83(66-97)$ & 89 (71-109) & $0.01^{*}$ \\
\hline $\begin{array}{l}\text { Mekanik ventilasyon süresi } \\
\text { (saat) }\end{array}$ & $6(5-8)$ & $6(6-8)$ & $6(6-8)$ & 0.92 \\
\hline YBÜ kalış süresi (gün) & $3(2-4)$ & $3(2-4)$ & $3(2-4)$ & 0.66 \\
\hline Hastane kalış süresi (gün) & $8(6-13)$ & $8(6-15)$ & $8(6-13)$ & 0.75 \\
\hline Hastane içi mortalite & $2(1,4)$ & $8(12,3)$ & $10(4,7)$ & $<0.001^{*}$ \\
\hline Takip süresi (yıl) & $1,6(1,4-1,7)$ & $\begin{array}{l}1.5 \\
1,6)\end{array}$ & $1,6(1,4-1,6)$ & 0.33 \\
\hline Geç dönem mortalite & $1(0,7)$ & $3(4,6)$ & $4(1,9)$ & $0.05^{*}$ \\
\hline
\end{tabular}

$A B H$, postoperatif komplikasyonlara ve erken dönem mortaliteye neden olduğundan erken dönemde tespit edilmelidir $(19,20)$. Postoperatif potansiyel komplikasyon- 
ların ciddiyeti RIFLE ile saptanan ABH'nin şiddeti ile doğru orantılıdır $(21,22)$.

Yapılan çalışmalarda, ABH gelişmiş hastalarda geç dönemdeki mortalite oranının yüksek olduğu ve mortalitenin $\mathrm{ABH}$ şiddetiyle orantılı olarak arttığı gösterilmiştir $(22,23)$. $\mathrm{Bu}$ çalışmalara benzer şekilde, çalışmamızda da $A B H$ gelişmiş grupta postoperatif potansiyel komplikasyonlar (solunumsal komplikasyonlar, kanama nedeniyle revizyon, IABP ve hemodiyaliz intiyacı) anlamlı olarak daha fazlaydı. Ek olarak, ABH'nin şiddeti arttıkça bu komplikasyonların şiddetinin de arttığını gözlemledik. Dahası, ABH gelişmiş hastalarda hastane içi mortalite oranı daha yüksekti ve özellikle de evre F'deki hastalar en yüksek hastane içi mortaliteye sahipti. Çalışmamızda elde ettiğimiz bu bulgular, post operatif dönemde gelişen $A B H$ 'nin kötü prognostik olaylara ilişkisi olduğu bilgisini desteklemektedir.

$\mathrm{ABH}$ gelişimi, preoperatif dönemdeki komorbid faktörlerle ilişkilidir $(5,6)$. Ancak ABH'nin patofizyolojisi multifaktöryeldir (24). Kardiyovasküler cerrahiden sonra gelişen ABY'ye sebep olarak yetersiz kardiyak performans, renal arterlerde meydana gelen ateroskleroz ve hipoksemi gösterilmiştir. Tüm bu faktörler, nedeni bilinmeyen renal iskemiye neden olmaktadırlar (25). Kalp cerrahisinde kullanılan kardiyopulmoner baypass cihazına bağlı pulsatil perfüzyon, pro-inflamatuar mediatörlerin salınımı ve mikroemboliler de ABH'ye neden olur (19). KPB süresi, kalp cerrahisi sonrasında gelişen $A B H$ 'nin en önemli risk faktörüdür $(5,7)$. Çalışmamızda da, literatür ile uyumlu olacak şekilde komorbid faktörlerin ve KPB süresindeki artışın $A B H$ sıkığını artırdığını saptadık. Artmış KPB süresinin $A B H$ ile ilişkisi; kardiyopulmoner cihazının yarattığı perfüzyon bozuklukları, inflamatuvar mediatörler ve tespit edilemeyen mikroemboliler ile açıklanabilir. Buna ek olarak, komorbid faktörlerin de renal perfüzyonu bozarak $\mathrm{ABH}$ gelişimine katkıda bulunabileceğini düşünmekteyiz.

$A B H$ tedavisindeki en önemli basamak $A B H$ 'nin erken aşamada tespit edilmesidir (26). ABH, erken evrede tedavi edilirse komplikasyonların ortaya çıkması önlenebilir (6). RIFLE sınıflaması, ABH'yi erken evrede saptayabildiğinden tedaviye yön verebilir. $A B H$ tedavisinde; loop diüretikleri, vazodilatatörler ve dopamin kullanımaktadır. Böbrek perfüzyonunu bozan hipotansiyonun düzeltilmesi özellikle önemlidir (27). Ortalama arter basıncı 70 mmHg'nın üzerinde kaldığı sürece, renal perfüzyon sağlanır ve $A B H$ gelişimi engellenir. $H T, K K Y$ ve DM'si olan hastalar perfüzyon basıncındaki değişiklikleri çok iyi tolere edemezler ve $\mathrm{ABH}$ gelişimine daha yatkındırlar (28). Uzun KBP süresinden kaçınılması, operasyon sırasında ortalama arter basıncının sağlanması ve aneminin düzeltilmesi ile ABH gelişme riski azaltılabilir $(29,30)$. Özellikle $\mathrm{ABH}$ gelişme riski yüksek olan komorbid durumlara sahip olan hastalarda operasyon öncesi dönemde gerekli tedbirler mutlaka alınmalıdır. Bu hastalarda kan şekerinin optimal seviyelerde tutulması, kan basıncının regüle edilmesi, KOAH tedavisine operasyon öncesi dönemde başlanması ve KKY'nin kompanse hale getirimesi ABH'nin gelişimini azaltacaktır.

Tablo 4. RIFLE evrelerine göre postoperatif sonuçlar

\begin{tabular}{|c|c|c|c|c|c|}
\hline Değişkenler & $\begin{array}{l}\text { ABH } \\
\text { olmayan } \\
\text { (n: 148) }\end{array}$ & $\begin{array}{l}\text { Evre } \\
\mathrm{R} \\
(\mathrm{n}: \\
41)\end{array}$ & $\begin{array}{l}\text { Evre I } \\
\text { (n:15) }\end{array}$ & $\begin{array}{l}\text { Evre } \\
\text { F } \\
(n: 9)\end{array}$ & $\begin{array}{l}\mathbf{P} \\
\text { Değeri }\end{array}$ \\
\hline $\begin{array}{lr}\text { Greft } & \text { stenozu } \\
\text { nedeniyle } & \text { erken } \\
\text { müdahale } & \\
\end{array}$ & $3(2,0)$ & $\begin{array}{l}3 \\
(7,3)\end{array}$ & 0 & $\begin{array}{l}1 \\
(11,1)\end{array}$ & 0.32 \\
\hline IABP & $5(3,4)$ & $\begin{array}{l}3 \\
(7,3)\end{array}$ & $\begin{array}{l}2 \\
(13,3)\end{array}$ & $\begin{array}{l}2 \\
(22,2)\end{array}$ & 0.44 \\
\hline $\begin{array}{l}\text { Düşük kardiyak debi } \\
\text { sendromu }\end{array}$ & $20(13,5)$ & $\begin{array}{l}5 \\
(12,2)\end{array}$ & $\begin{array}{l}4 \\
(26,7)\end{array}$ & $\begin{array}{l}3 \\
(33,3)\end{array}$ & 0.22 \\
\hline Atriyal fibrilasyon & $35(23,6)$ & $\begin{array}{l}12 \\
(29,3)\end{array}$ & $\begin{array}{l}3 \\
(20,0)\end{array}$ & $\begin{array}{l}2 \\
(22,2)\end{array}$ & 0.75 \\
\hline Diğer aritmiler & & & & & 0.73 \\
\hline $\begin{array}{l}\text { Ventriküler } \\
\text { fibrilasyon }\end{array}$ & $1(0,7)$ & $\begin{array}{l}1 \\
(2,4)\end{array}$ & $\begin{array}{l}1 \\
(6,7)\end{array}$ & 0 & \\
\hline $\begin{array}{l}\text { Ventriküler } \\
\text { taşikardi }\end{array}$ & $1(0,7)$ & $\begin{array}{l}1 \\
(2,4)\end{array}$ & 0 & 0 & \\
\hline $\begin{array}{l}\text { Solunumsal kompli- } \\
\text { kasyonlar }\end{array}$ & $13(8,8)$ & $\begin{array}{l}5 \\
(12,2)\end{array}$ & $\begin{array}{l}3 \\
(20,0)\end{array}$ & $\begin{array}{l}4 \\
(44,4)\end{array}$ & 0.08 \\
\hline $\begin{array}{l}\text { Nörolojik komplikas- } \\
\text { yonlar }\end{array}$ & $9(6,1)$ & $\begin{array}{l}1 \\
(2,4)\end{array}$ & $\begin{array}{l}1 \\
(6,7)\end{array}$ & $\begin{array}{l}2 \\
(22,2)\end{array}$ & 0.15 \\
\hline Kanama revizyonu & $2(1,4)$ & $\begin{array}{l}3 \\
(7,3)\end{array}$ & 0 & $\begin{array}{l}2 \\
(22,2)\end{array}$ & 0.12 \\
\hline Sepsis & $10(6,8)$ & $\begin{array}{l}4 \\
(9,8)\end{array}$ & 0 & $\begin{array}{l}2 \\
(22,2)\end{array}$ & 0.12 \\
\hline Hemodiyaliz & 0 & $\begin{array}{l}1 \\
(2,4)\end{array}$ & $\begin{array}{l}1 \\
(6,7)\end{array}$ & $\begin{array}{l}3 \\
(33,3)\end{array}$ & $<0.001^{*}$ \\
\hline Hastane içi mortalite & $2(1,4)$ & $\begin{array}{l}2 \\
(4,9)\end{array}$ & $\begin{array}{l}2 \\
(13,3)\end{array}$ & $\begin{array}{l}4 \\
(44,4)\end{array}$ & $0.02^{*}$ \\
\hline $\begin{array}{l}\text { Mekanik ventilasyon } \\
\text { süresi (saat) }\end{array}$ & $6(5-8)$ & $\begin{array}{l}7(6- \\
8)\end{array}$ & $\begin{array}{l}6 \\
8)\end{array}$ & $\begin{array}{l}5(3- \\
18)\end{array}$ & 0.38 \\
\hline $\begin{array}{l}\text { YBÜ kalış süresi } \\
\text { (gün) }\end{array}$ & $3(2-4)$ & $\begin{array}{l}3 \\
4)\end{array}$ & $\begin{array}{l}3 \\
4)\end{array}$ & $\begin{array}{l}2 \\
3)\end{array}$ & 0.06 \\
\hline $\begin{array}{l}\text { Hastane kalış süresi } \\
\text { (gün) }\end{array}$ & $8(6-13)$ & $\begin{array}{l}9(6- \\
16)\end{array}$ & $\begin{array}{l}8 \\
9)\end{array}$ & $\begin{array}{l}20(4- \\
38)\end{array}$ & 0.28 \\
\hline $\begin{array}{l}\text { Geç dönem mortali- } \\
\text { te }\end{array}$ & $1(0,7)$ & 0 & 0 & $\begin{array}{l}3 \\
(33,3)\end{array}$ & $<0.001^{*}$ \\
\hline
\end{tabular}

Kısaltmalar; Bakınız Tablo 5

Çalışmamızı sınırlayan unsurlar, geriye dönük natürde olması ve izole KABG hastalarından oluşmasıdır.

Sonuç olarak, KABG cerrahisinden sonra gelişen $A B H$, artmış postoperatif morbidite ve mortalite ile ilişkilidir. $\mathrm{ABH}$ tespitinde RIFLE sınıflamasının kullanıışının kolay ve maliyetsiz olması, $A B H$ 'yi klâsik $A B Y$ tanımlamasından üstün kılar. Ayrıca $A B H$ 'nin şiddetini erken aşamada tespit ederek erken tedaviye imkân sağlar. 
Tablo 5. Univaryant ve multivaryant analiz sonucunda önemli postoperatif sonuçlara etki eden bağımsız prediktörler

\begin{tabular}{|c|c|c|c|c|}
\hline \multirow[t]{2}{*}{ Değişkenler } & \multirow{2}{*}{$\begin{array}{l}\text { Univaryant } \\
\text { analiz } \\
\text { P }\end{array}$} & \multicolumn{2}{|c|}{ Multivaryant analiz } & \multirow[b]{2}{*}{$\mathbf{P}$} \\
\hline & & OR & $\begin{array}{l}\% 95 \mathrm{Cl} \text { alt ve üst } \\
\text { değer }\end{array}$ & \\
\hline \multicolumn{5}{|l|}{$\mathrm{ABH}$ için } \\
\hline KKY & 0.02 & 3.07 & $1.06-8.92$ & 0.04 \\
\hline Periferik arter hastalığı & 0.05 & - & - & - \\
\hline Hipertansiyon & 0.03 & 2.31 & $1.16-4.61$ & 0.02 \\
\hline KPB süresi & 0.03 & 1.01 & $1.0-1.02$ & 0.03 \\
\hline Reoperasyon & 0.10 & - & - & - \\
\hline IABP & 0.04 & - & - & - \\
\hline Solunumsal komplikasyon & 0.05 & 2.89 & $1.14-7.29$ & 0.03 \\
\hline Kanama revizyonu & 0.03 & - & - & - \\
\hline Evre R ABH için & & - & - & - \\
\hline Periferik arter hastalığı & 0.02 & 4.43 & $1.19-16.42$ & 0.03 \\
\hline Hipertansiyon & 0.10 & & & \\
\hline $\mathrm{KOAH}$ & 0.04 & 2.13 & $1.0-4.66$ & 0.05 \\
\hline MI öyküsü & 0.06 & - & - & - \\
\hline Reoperasyon & 0.10 & - & - & - \\
\hline Kanama revizyonu & 0.10 & - & - & - \\
\hline Evre I ABH için & & - & - & - \\
\hline VKI & 0.09 & - & - & - \\
\hline KKY & 0.10 & - & - & - \\
\hline KPB süresi & 0.06 & 1.02 & $1.01-1.03$ & 0.05 \\
\hline Hastane kalış süresi & 0.10 & - & - & - \\
\hline Evre $F A B H$ için & & - & - & - \\
\hline KKY & 0.01 & 5.97 & $1.16-30.70$ & 0.03 \\
\hline IABP & 0.04 & - & - & - \\
\hline Solunumsal komplikasyon & 0.001 & 5.01 & $1.09-23.65$ & 0.04 \\
\hline Nörolojik komplikasyon & 0.06 & - & - & - \\
\hline Kanama revizyonu & 0.001 & - & - & - \\
\hline Sepsis & 0.10 & - & - & - \\
\hline Hastane içi mortalite & & - & - & - \\
\hline VYA* & 0.02 & - & - & - \\
\hline Yaş & 0.02 & 1.18 & $1.02-1.23$ & 0.02 \\
\hline SVO & 0.10 & - & - & - \\
\hline KKY & 0.001 & 10.88 & $1.08-110.15$ & 0.04 \\
\hline MI öyküsü & 0.04 & 8.54 & $1.0-76-64$ & 0.05 \\
\hline Hipotermi* & 0.10 & - & - & - \\
\hline Kros klemp süresi & 0.001 & - & - & - \\
\hline KPB süresi & 0.001 & 1.05 & $1.01-1.09$ & 0.02 \\
\hline Reoperasyon & 0.01 & - & - & - \\
\hline IABP & $<0.001$ & 41.56 & $3.26-530.27$ & 0.01 \\
\hline $\mathrm{ABH}$ & 0.001 & 11.78 & $1.15-120.72$ & 0.04 \\
\hline Mekanik ventilasyon süresi & 0.02 & - & - & - \\
\hline
\end{tabular}

ABH: Akut böbrek hasarı, Cl: Confidence interval, HT: Hipertansiyon, IABP: Intra aortik balon pompası, KKY: Konjestif kalp yetmezliği, KOAH: Kronik obstrüktif akciğer hastalığı, KPB: Kardiyo pulmoner bypass, MI: Miyokardiyal infarktüs,

OR: Odds ratio, PAH: Periferik arter hastalığı, SVO: Serebro vasküler olay,

VKI: Vücut kitle indeksi, VYA vücut yüzey alanı

*: Ters orantı

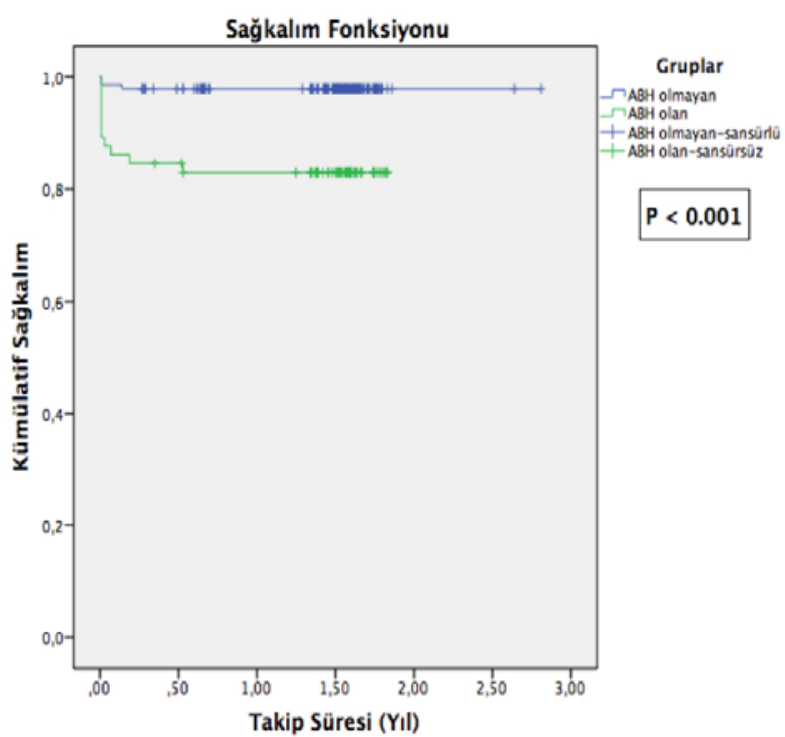

Şekil 2. ABH olan ve olmayan hastalara ait sağkalım eğrileri ve karşılaştırılması

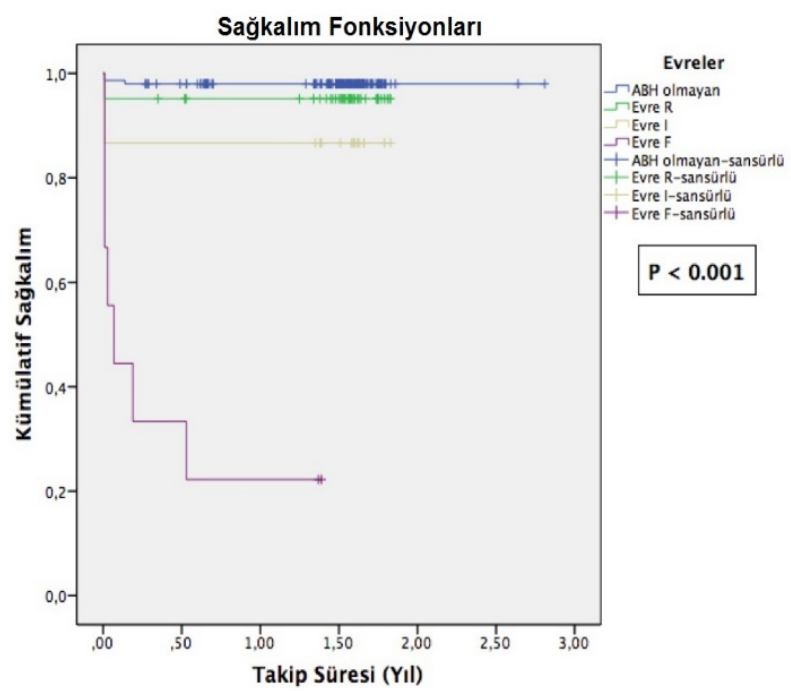

Şekil 3. $A B H$ evrelerine göre sağkalım eğrileri ve karşılaştırılması

Tablo 6. Geç mortalite için peroperatif ve postoperatif bağımsız prediktörler (Cox regresyon analizi)

\begin{tabular}{|c|c|c|c|c|}
\hline Değişkenler & HR & $\begin{array}{l}95 \% \mathrm{Cl} \\
\text { alt değer }\end{array}$ & $\begin{array}{l}95 \% \mathrm{Cl} \\
\text { üst değer }\end{array}$ & $\begin{array}{l}\mathbf{P} \\
\text { Değeri }\end{array}$ \\
\hline Yaş & 1.08 & 1.0 & 1.17 & 0.05 \\
\hline KKY & 3.97 & 1.11 & 14.23 & 0.03 \\
\hline MI öyküsü & 6.18 & 1.66 & 22.95 & 0.01 \\
\hline KPB süresi & 1.02 & 1.0 & 1.03 & 0.04 \\
\hline Reoperasyon & 9.75 & 2.2 & 43.19 & 0.001 \\
\hline $\mathrm{ABH}$ & 9.52 & 1.91 & 47.55 & 0.01 \\
\hline
\end{tabular}

ABH: Akut böbrek hasarı, Cl: Confidence interval, HR: Hazard ratio, IABP: Intra aortik balon pompası, KKY: Konjestif kalp yetmezliği, KPB: Kardiyopulmoner bypass, Ml: Miyokardiyal infarktüs

Harran Üniversitesi Tıp Fakültesi Dergisi (Journal of Harran University Medical Faculty) 2019;16(3):463-469. 


\section{Kaynaklar}

1- Bove T, Monaco F, Covello RD, Zangrillo A. Acute renal failure and cardiac surgery. HSR Proc Intensive Care Cardiovasc Anesth. 2009;1(3):13-21.

2- Hobson CE, Yavas S, Segal MS, Schold JD, Tribble CG, Layon AJ, et al. Acute kidney injury is associated with increased long-term mortality after cardiothoracic surgery. Circulation. 2009;119(18):2444-53.

3- Arora $P$, Kolli $H$, Nainani $N$, Nader N, Lohr J. Preventable risk factors for acute kidney injury in patients undergoing cardiac surgery. J Cardiothorac Vasc Anesth. 2012;26(4):687-97.

4- Bellomo R, Auriemma S, Fabbri A, D'Onofrio A, Katz N, McCullough $\mathrm{PA}$, et al. The pathophysiology of cardiac surgery associated acute kidney injury (CSA-AKI). Int J Artif Organs. 2008;31(2):166-78.

5- Lagny MG, Jouret F, Koch JN, Blaffart F, Donneau AF, Albert A, et al. Incidence and outcomes of acute kidney injury after cardiac surgery using either criteria of the RIFLE classification. BMC Nephrol. 2015;16:76.

6- Duthie FA, McGeehan P, Hill S, Phelps R, Kluth DC, Zamvar V, et al. The utility of the additive EuroSCORE, RIFLE and AKIN staging scores in the prediction and diagnosis of acute kidney injury after cardiac surgery. Nephron Clin Pract. 2014;128(1-2):29-38.

7- Yamauchi T, Miyagawa S, Yoshikawa Y, Toda K, Sawa Y; Osaka Cardiovascular Surgery Research (OSCAR) Group. Risk index for postoperative acute kidney injury after valvular surgery using cardiopulmonary bypass. Ann Thorac Surg. 2017;104(3):868-75.

8- Eknoyan G. Emergence of the concept of acute renal failure. Am J Nephrol. 2002;22(2-3):225-30.

9- Mehta RL, Pascual MT, Soroko S, Savage BR, Himmelfarb J, Ikizler TA, et al. Program to Improve Care in Acute Renal Disease. Spectrum of acute renal failure in the intensive care unit: The PICARD experience. Kidney Int. 2004;66(4):1613-21.

10- Palevsky PM. Epidemiology of acute renal failure: The tip of the iceberg. Clin J Am Soc Nephrol. 2006;1(1):6-7.

11- Ympa YP, Sakr Y, Reinhart K, Vincent JL. Has mortality from acute renal failure decreased? A systematic review of the literature. Am J Med. 2005;118(8):827-32.

12- Metnitz PG, Krenn CG, Stelzer H, Lang T, Ploder J, Lenz K, et al. Effect of acute renal failure requiring renal replacement therapy on outcome in critically ill patients. Crit Care Med. 2002;30(9):2051-58.

13- Dedemoğlu M, Öztürk F, Günay D, Dağlı M, Çelik EC, Sezgin M, et al. The evaluation of acute kidney injury after pediatric heart surgery by using "Pediatric RIFLE Criteria". Kosuyolu Heart J. 2019;22(1):4853.

14- Xiong J, Tang X, Hu Z, Nie L, Wang Y, Zhao J. The RIFLE versus AKIN classification for incidence and mortality of acute kidney injury in critical ill patients: A meta-analysis. Sci Rep. 2015; 5: 17917.

15- Lopes, JA, Jorge S. The RIFLE and AKIN classifications for acute kidney injury: a critical and comprehensive review. Clin Kidney J. 2013;6(1):8-14

16- Levey AS, Coresh J, Greene T, Stevens LA, Zhang YL, Hendriksen S, et al.Chronic Kidney Disease Epidemiology Collaboration. Ann Intern Med. 2006;145(4):247-54.

17- Bellomo R, Ronco C, Kellum JA, Mehta RL, Palevsky P; Acute Dialysis Quality Initiative Work Group. Acute renal failure-definition, outcome measures, animal models, fluid therapy and information technology needs: the Second International Consensus Conference of the Acute Dialysis Quality Initiative (ADQI) Group. Crit Care. 2004;8(4):R204-12.

18- Englberger L, Suri RM, Schaff HV. RIFLE is not RIFLE: on the comparability of results. Crit Care. 2009;13(6):429.

19- Liu YJ, Sun HD, Chen J, Chen MY, Ouyang B, Guan XD. Klotho: a novel and early biomarker of acute kidney injury after cardiac valve replacement surgery in adults. Int J Clin Exp Med. 2015;8(5):7351-58. 20- Vives M, Wijeysundrea D, Marczin N, Monedero P, Rao V. Cardiac surgery-associated acute kidney injury. Interact Cardiovasc Thorac Surg. 2014;18(5):637-45.
21- Englberger L, Suri RM, Li Z, Casey ET, Daly RC, Dearani JA, et al. Clinical accuracy of RIFLE and Acute Kidney Injury Network (AKIN) criteria for acute kidney injury in patients undergoing cardiac surgery. Crit Care. 2011;15(1):R16.

22- D'Onofrio A, Cruz D, Bolgan I, Auriemma S, Cresce GD, Fabbri A, et al. RIFLE criteria for cardiac surgery-associated acute kidney injury: risk factors and outcomes. Congest Heart Fail. 2010; 16 Suppl 1: S326.

23- Lopez-Delgado JC, Esteve F, Torrado H, Rodrigues-Castro D, Carrio ML, Farrero E, et al. Influence of acute kidney injury on shortand long-term outcomes in patients undergoing cardiac surgery: risk factors and prognostic value of a modified RIFLE classification. Crit Care. 2013;17(6):R293.

24- Erpicum P, Detry O, Weekers L, Bonvoisin C, Lechanteur C, Briquet $A$, et al. Mesenchymal stromal cell therapy in conditions of renal ischaemia/reperfusion. Nephrol Dial Transplant. 2014;29(8):1487-93.

25- Chertow GM, Lazarus JM, Christiansen CL, Cook EF, Hammermeister KE,Grover F,et al. Preoperative renal risk stratification. Circulation .1997;18:95(4):878-84.

26- Garrido JM, Candela-Toha AM, Parise-Roux D, Tenorio M, Abraira $\checkmark$, Del Rey JM, et al. Impact of a new definition of acute kidney injury based on creatinine kinetics in cardiac surgery patients: a comparison with the RIFLE classification. Interact Cardiovasc Thorac Surg. 2015;20(3):338-44.

27- Schetz M, Bove T, Morelli A, Mankad S, Ronco C, Kellum JA. Prevention of cardiac surgery-associated acute kidney injury. Int J Artif Organs. 2008;31(2):179-89.

28- Carvounis CP, Nisar S, Guro-Razuman S. Significance of the fraction alexcretion of urea in the differential diagnosis of acute renal failure. Kidney Int 2002;62:2223-9.

29- Haase M, Bellomo R, Story D, Letis A, Klemz K, Matalanis G, et al. Effect of mean arterial pressure, haemoglobin and blood transfusion during cardiopulmonary bypass on postoperative acute kidney injury. Nephrol Dial Transplant. 2012;27(1):153-60.

30- Oliver E, Carrio ML, Rodríguez-Castro D, Javierre C, Farrero E, Torrado $\mathrm{H}$, et al. Relationship among haemoglobin level, packed red cell transfusion and clinical outcomes in patients after cardiac surgery. Intensive Care Med. 2009;35(9):1548-55. 